\title{
The Role of Psychological Stress on the Performance of the Social Workers Working in the Hope Complexes of Mental Health in Northern Borders
}

\begin{abstract}
Fayes Suryan Al Anazi Prof. Ayed Wraikat

The study aimed to know the role of psychological stress in the performance of social workers in Al-Amal mental health complexes in the northern border region. In order to achieve this goal, a two-part questionnaire was designed. The first part included demographic and social information, while the second part formed of five axes (anxiety Depression, mental health, handicaps and the role of mental health management). The sample consisted of eightyfive subjects .The results of the study showed the following:

-There are statistically significant differences according to the effect of social pressures, according to the family's support among social workers at Al-Amal Complex for Mental Health in the northern region.

-There are statistically significant differences according to the effect of economic pressures according to the income level of the social workers in Al-Amal Complex for Mental Health in the northern region.

-There are statistically significant differences according to the effect of psychological stress on social workers in Al-Amal Complex for Mental Health in the northern region, according to psychological rigidity.
\end{abstract}

Keywords: social pressure, social workers.

DOI: $10.7176 / \mathrm{JEP} / 11-21-06$

Publication date:July $31^{\text {st }} 2020$

\section{Introduction}

Human pressure is an old human phenomenon created with the very existence of man, because God Almighty said: (We created man in a liver) (Surat al-Balad: Verse 4) (Saudi, 2009) as life is nothing but suffering, hardship, and pressure, since man has been since Beginning of the creation of the universe over millions of years, he lived in search of stability and safety, running behind the comfort that balance gives him, as he seeks to reduce the burden of life on his shoulders.

In view of the rapid developments and changes in all areas of life, "psychological stress" has become one of the most important features of the times, as it has become part of the human life as it witnesses many challenges. Pressures of all kinds are the product of accelerated civilization progress that leads to the production of deviations that are a burden on the ability of Resistance to human endurance, "psychological stress" has become a feature of contemporary life and an experience that the individual lives on a daily basis, so some researchers have called this era the "psychological stress" "(McCurry, 2007).

Despite the multiplicity of researchers' opinions on what the pressures are, they meet on the necessity of providing stressful situations followed by a response from the individual to these situations, as Lazarus sees that "when a person realizes his inability to balance between the requirements of the positions and his ability to respond to these requirements in an important situation, it is He feels the dominance of pressure on him, but if he can meet these requirements, then the pressure is acceptable "(Sharaf al-Din, 1997).

Several studies have indicated that life pressures play an important role in the emergence of psychosomatic symptoms in general because of the presence of physiological changes related to the reactions of the body towards stresses that have a close causal relationship to human health (Saudi, 2009) and the physical and psychological diseases that it afflicts, especially phallic symptoms. (Bouchaaria, 2012), when scholars and researchers gave special attention to studying psychological pressure, given its negative effects on the individual and society (Saudi, 2009), as many specialized studies have shown that the pressures workers often experience in work environments does not only affect their condition Health and psychological disturbance, anxiety, fear, frustration, and anger, but it is also reflected in the levels of their performance of their work, and then their ability to work. Which hinders organizations and institutions in reaching their goals that they are working towards. (Saudi, 2009).

"Selye", the endocrinologist at the Canadian University of Montreal, is the first to provide a translation of a sense of the concept of stress to scientific life, and this term refers to fatigue and distress, as the word pressure is one of the common words used today, as most other psychological phenomena such as conflict, anxiety and frustration, which are among The nature of human existence, as the individual's life is not free from it from time to time and sometimes most of the time, and on this basis the concept of pressure has become a basic term in different sciences and disciplines such as medicine, psychiatry, psychology ... and other sciences, and the concept of stress has also become a common concept in The academic field in the field of social work and health.

"Psychological pressures" are defined as "external pressure factors that affect the individual partially or completely to a high degree, have a sense of tension, and the increase of this pressure loses its ability to balance, and may lead to stress and then psychological burn" 
As the interest in the social service profession forces us to care for workers in this field where the social worker is exposed to many pressures that have negative dimensions on him, which reduces the effectiveness of his professional role and affects him by exhausting all energies to deal with the demands of work that lead his abilities, which leads him to Psychiatric illnesses are physical and lead to inefficiency. (Al-Rantisi, 2015). The need came to study the role of "psychological stress" in the performance and work of social workers in the Amal Health Complexes in the northern border region.

First: The study problem:

Numerous studies such as "Micah Edelson1, Tali Sharot, Raymond J. Dolan, Yadin Dudai, 2011" indicated that stress can push people to form false memories, and they can replace their true memories with fake ones, and consider them a reality that actually happened in response to those pressures They face, as "psychological pressures" contribute greatly to impeding the quality of the professional performance of social workers, as they leak and form in the workspace of the social worker in the Amal Health Complexes in the northern border region of personal, professional and institutional pressures; Which makes the social worker has no ability to work or distinguish or complete what he was assigned to do, and the study problem can be summarized by knowing the role of "psychological pressures" on the performance of workers (social workers) in the northern border region from their point of view?

\section{Theoretical framework previous studies: First: previous studies \\ Arab Studies}

1- Al-Rantisi (2017) The current study aimed to determine the level and quality of pressures that social workers are exposed to in the directorates of social affairs in the Gaza Strip, and to determine the most pressure on them, and this study is considered descriptive and analytical studies, and the study used the social survey in a comprehensive survey method for all specialists The social workers working in all directorates of social affairs deployed in the Gaza Strip, numbering (135) singles, and used the pressure gauge to reveal the results of the study, and the results of the study revealed that most of the pressure on social workers in the directorates of social affairs leading to the state of professional fatigue is: pressure due to factors Motivational by $70.9 \%$, followed by pressure due to organizational and administrative factors by $68.7 \%$, followed by pressure due to the institution in which the social worker worked with $66.7 \%$, followed by pressure due to the quality and nature of clients by $59.7 \%$, followed by pressure due to the status of the profession within society by $54.9 \%$, followed by pressure due to the personality of the social worker himself with 53\%, followed by pressure returned to the world Findings within the organization reached $51.2 \%$, and finally the pressure attributed to the family and the parents by $47.1 \%$. The study results also showed that there are no statistically significant differences between the pressures that social workers are exposed to due to the gender variable, the experience variable and the workplace variable.

2- Al-Halim (2015) The study aimed to reveal life stress and confrontational skills. The article pointed out that mankind lived through a stage of development and departure imposed by scientific and technological progress and social development, and that despite the enjoyment of life by man, he is still far from happiness, security and psychological satisfaction; As a result of the complexity of his life and his transformation from simplicity to composition, and from ease to complexity and the pursuit of ambiguous goals that can no longer bring him happiness, reassurance and desired psychological security. The article also clarified that the phenomenon of "psychological stress" is one of the most important topics that occupied the thought and interest of a large number of individuals, especially in recent years. The article also showed that there is a certain amount of pressure that is necessary for life. Excessive or exaggerated pressures have devastating consequences, the most prominent of which is known as psychological burning. The article touched upon the knowledge of the various symptoms of psychological pressure, in order to be able to help reduce stress and use the most appropriate strategies to manage "psychological stress" and to help the self or others must know what happened. The article concluded that the pressures, whether from work or from people, affect the nerves, so it is necessary to try to reduce or eliminate them, and how to deal with them by learning how to counter them and withstand them. This abstract was written by Dar Al-Mandoom 2018

1- Kandil (2015) This study aims to identify the nature of the causes that lead to occupational pressures facing the social worker in the medical field, in addition to identifying the nature of the negative effects of the professional pressures that the social worker faces in the medical field by identifying the negative effects of the professional pressure on the aspects The physical and health of the social worker, as well as the negative effects of professional pressure on the psychological aspects of the social specialist, and identify the most important proposals to overcome the negative effects of the professional pressure facing the medical social specialist, which clarified the attempt to develop and design a proposed counseling program from the perspective of community service to confront the negative effects of the professional pressure that Facing the social worker in the medical field in the Kingdom of Saudi Arabia, the researcher relied on the analytical approach (comprehensive social survey), and the study concluded with the most important summary results. 
2- Shawkat (2013) "Psychological stress" is a common psychological phenomenon in our daily life, and one of the main concepts of understanding and interpreting behavior is that a person feels pleasure and pleasure when he reaches his needs and feels distress or psychological pressure if he is prevented from satisfying those needs, and when we talk about "Psychological Stress "We are talking about a problem that has accompanied man since he was on the ground. Our present age is the era of "psychological stress", due to several reasons, the most important of which is the strong competition for specific resources, the emergence of economic, social and political crises, wars and human and natural disasters, all of which are features of the modern era. The impact of "psychological pressure" extends to various aspects of the worker, his physical and psychological health in addition to The productivity and performance of the organization, which reflects negatively on the whole society, hence the importance of caring for finding appropriate solutions to deal with "psychological stress" to reduce it or keep it within the normal level. In light of the data, the current research objectives were formulated: 1- Measuring "psychological pressures" among social researchers working in prisons (first Rusafa prison). 2- Measuring job satisfaction with social researchers working in prisons (first Rusafa prison). 3- Finding the relationship between "psychological stress" and job satisfaction with social researchers working in prisons (first Rusafa prison). To achieve the goals of the research, the researcher prepared two measures, the first to measure "psychological stress" and the second to measure job satisfaction. It consisted of (21) items. The sample was chosen by simple random method. After collecting the data, it was processed using the appropriate statistical means. The research reached the following results: 1-The sample has Psychological stress. 2- The sample has job satisfaction>

3- Al Dhafiri (2011) This study examines the effect of "psychological stress" during work on the performance of social workers working in primary schools in the State of Kuwait, and the impact of social support in the process of facing problems. The study included a sample of 233 social workers who responded to the study out of 262 social workers distributed among the 136 primary schools in Kuwait as a comprehensive sample for all schools. The results related to Pearson Lab, ANOVA analysis, psychological tests, the measures used «Seoul 1983», the social adjustment scale and the Center for the Study of Depression «Radloff 1977» showed that the "psychological pressures" that social workers go through in carrying out their work were subjected to the measurement using a modified version of the events scale Difficult daily life, as it was found that the psychological pressures that social workers are going through due to work pressures were significant at a rate of " 300 " "on the scale of the established social adjustment. The results also showed that there is a statistically significant relationship between work conditions and "psychological stress". The search for social support establishes the relationship between daily work events and the "psychological stress" that a social worker faces. The study also reached some important results, many of which are compatible with the literature related to this research, as well as with the hypotheses of the study.

\section{Foreign studies:}

1- Wagaman Study, Jennifer, (Clara, Elizabeth A. Segal, 2015) (Social workers are at risk of developing fatigue and stress from secondary trauma (STS) as a result of the nature of their work and the contexts in which they work. Little attention has been paid to factors within the control of A social worker that may prevent fatigue and STS and increase compassion satisfaction. Empathy, which is a combination of physiological and cognitive processes, may be a tool to help treat fatigue and STS. This article examines the results of a study of social workers (number $=173$ ) that explores the relationship between components of empathy Fatigue, STS, and Empathy Satisfaction using the Empathy Assessment Index and Professional Quality of Life tools. It was assumed that higher levels of empathy would be associated with lower levels of fatigue and STS, and higher levels of empathy satisfaction. Results indicate that compassion components may prevent or reduce fatigue and STS with Increased satisfaction with empathy. This sympathy should be included in training and education throughout the life of the social worker. 2- 2008 (Madeleine \& Kim,) This study examines the main and interactive effects of the role of stress, job independence, and social support in predicting fatigue and intent to spin among social workers. This study included a sub-sample of 346 social workers who were identified through a randomized cross-sectional survey of 1,500 registered social workers in California. Adjusted by age, gender, organizational tenure, and annual salary, structural formula analyzes revealed that role pressure had a direct positive impact on fatigue. Social support variables and job independence had a direct negative impact on intention to turn, but not on fatigue. The results showed that job independence interacted with role pressures in predicting fatigue, while social support interacted with role pressures in predicting turnover. The results of the study indicate that the creation of decentralized working conditions is necessary to prevent fatigue, and that building supportive working conditions is necessary to retain social workers who have significant pressure on the role.

\section{Commenting on previous studies:}

It is clear from the review of previous studies, the large number of scientific research that dealt with the topic of "psychological and social stresses", but there is a dearth of researches that linked between "psychological and social stresses" that society affected as a result of the economic conditions that the whole world is going through 
in addition to the requirements of economic life, which leads To create pressure for coexistence at the level it hoped for.

\section{Theoretical framework:}

Social service is a set of values, based on respecting the human being, safeguarding his dignity and humanity, and preserving the confidentiality of information related to the situation, ensuring the freedom of the person to choose what he wants for himself according to his beliefs, and helps to invest and employ him to help himself by himself, and the social worker is a specialized person who has many features To make him successful in his work, by preparing and training him so that he can play his effective role and avoid the difficulties that hinder him in performing his work tasks to the fullest extent, except that social workers are human beings and prone to stress because they participate in their jobs that require a lot of psychological terms. The social worker's role is to provide a wide range of services from emotional support to situations, as social workers may interfere by providing individual or family counseling, providing group education or support, and working with community groups in developing resources to help patients meet their specific needs. As a result, the social worker is vulnerable to stress.

The role of the social worker, his work style, and his interference differ according to the situations and categories with which he works. The role of the social worker in the educational field differs from his role in the field of women's and children's rights from the field of addiction, and other areas, and despite these different areas, they are all based on three Main roles:

o The preventive role: The social worker takes the necessary preventive measures to reduce the spread of the social problem in which he works.

The developmental role: the work of the social worker develops the individual capabilities and skills of the groups he works with, and that helps open several areas for them to work, develop and succeed.

o The therapeutic role: The social worker works to get rid of the situation with which he works with from the social or psychological problems he suffers from, or to help in learning to accept them and how to deal with them, as is the solution in cases of physical disability, which constitute the primary barrier to preventing the achievement of the developmental role (tired bin Saleh bin Qahim, 2004, p. 25)

The job of the social worker in the hospital's medical field is an important element in medical treatment given the nature of the role the social worker plays through his cooperation with the medical team treating the patient's social problems. This is evident in the medical socialist's endeavor to achieve the following goals:

- Spreading awareness and healthy culture to prevent disease.

- Helping the patient to reach recovery as soon as possible.

- Linking the hospital to the outside community and its institutions.

- Eliminate the problems that the patient suffers from.

- Cooperating with officials to provide the required services to patients.

\section{The effect of "psychological stress" on a person}

The relationship between an individual's psychological stress and his health and physical condition is inverse. The higher the rate of psychological pressure on a person, the lower his overall health rate, due to physiological changes in the body. Any psychological effect has reactions in most parts of the body, called predisposition, and if the situation worsens under pressure on the individual, it may lead to serious diseases, despite many attempts to maintain health such as dieting, playing sports, and other preventive means And therapeutic. A study was conducted on a group of people whose purpose was to explain the psychological state and its effect on the human immune system, so the result was that the immune system decreased its concentration in the body when exposed to stress. And one of the studies that were conducted on the topic of mental disorders and their prevention showed that about 450 million people suffer from mental disorders throughout the world, and that a quarter of people will develop one or more mental disorders at some point in their lives, and that these disorders are not only an economic and social burden Rather, it poses a risk to physical health.

It is worth noting that there are many studies that have proven that social factors, satisfaction and psychological happiness have the greatest impact on maintaining physical health, among the diseases caused by stress and psychological pressure:

- Increased risk of developing a type of cancerous tumor; to weaken the immune system of the individual in the case of emotional emotion.

- The effect on the heart, which is linked to human heart attacks.

- arterial stenos is; And this is through a study conducted on people who have measured levels of the hormone cortical that is produced by the body (stress hormone) when a person is exposed to psychological pressures, and the release of which leads to narrowing of the arteries.

- $\quad$ anemia caused by loss of appetite; Because of stress and tension.

- The incidence of many other diseases, such as: backache, neck, shoulders, stomach, head, migraines, high 
pressure, and discoloration of the skin so that it becomes.

\section{Ninth: Procedural terms:}

\section{1- "Psychological Stress":}

Define what is and what are environmental events or stimuli that cause dysfunctional responses in individuals. (Abdullah Al-Deraibi, 2010, p. 676)

The researcher relied on the use of this definition as a procedural definition of the study. Glossary of psychoanalysis: it is all external factors that put pressure on the psychological state of the individual to a degree that makes him in a state of tension, anxiety and negative impact on his ability to achieve integration and balance in his personality, in addition to the loss of emotional equilibrium and the emergence of behavioral patterns New ones, and these pressures arise when the individual is faced with an urgent matter that requires the correct response to it or a demand that does not have sufficient capacity to fulfill it, or that it falls outside the limits of his ability. (Alaa Kamal Ahmad Muhammad Abdullah, 2018, p. 10) "Psychological stress" in this study has been defined through paragraphs (1-17).

2- "Social Worker": A person who performs his work in the light of the concept of the social service profession and on the basis of its philosophy is committed to its principles and ethical standards for solving social problems experienced by the individual.

\section{Fourth: The importance of the study:}

The importance of this research stems from the importance of studying the extent of the impact of "psychological stress" on the performance of social workers working in Al-Amal Health Complexes in the northern border region, as the role of social workers is an important role for society and that society in general needs to activate their roles by spreading a culture of social work and trying Reducing the pressures on them such as social, psychological and economic pressures, which hinders them from performing work, which affects the institutional work.

Fifth: The objectives of the study: The main objective of the research is:

The role of "psychological stress" on the performance of social workers working in Al-Amal mental health complexes in the northern borders

\section{There are several sub-goals in the primary goal:}

1. Knowing the role of concern over the performance of social workers working in Al-Amal mental health complexes in the northern borders from their point of view.

2. Knowing the role of depression on the performance of social workers working in Al-Amal mental health complexes in the northern borders from their point of view.

3. Knowing the role of mental health in the performance of social workers working in Al-Amal mental health complexes in the northern borders and their performance from their viewpoint.

4. Verifying the presence of statistically significant differences at the level of significance $(\alpha=0.05)$ between the estimates of the study sample individuals on mental and social health management in enhancing the performance of social workers working in Al-Amal mental health complexes in the northern borders due to variables (gender, educational qualification, years of service ).

5. Explain the most important psychological obstacles and challenges facing social workers working in Al-Amal mental health complexes in the northern borders.

6. Finding the most important means and suggested ways to activate the role of the Department of Mental and Social Health in enhancing the performance of social workers working in Al-Amal mental health complexes in the northern borders.

Sixth: Questions of the study: The study is based on answering the main question of the research, which is as follows: What is the impact of the role of social, economic and psychological pressures on the performance of social workers working in Al-Amal mental health complexes in the northern borders?

Research questions :

1. What is the role of concern for the performance of social workers working in Al-Amal mental health complexes in the northern borders?

2. What is the role of depression in the performance of social workers working in Al-Amal mental health complexes in the northern borders?

3. Is there a correlation between the mental health of social workers working in Al-Amal mental health complexes in the northern borders and their performance?

4. What is the level of mental and social health and the performance of social workers working in Al-Amal mental health complexes in the northern borders?

5. Are there statistically significant differences at the level of significance $(5=0.05)$ between the estimates of the study sample individuals on mental and social health management in enhancing the performance of social workers working in Al-Amal mental health complexes in the northern borders due to the variables (gender, educational 
qualification, years of service) ?

6. What are the psychological obstacles and challenges facing social workers working in Al-Amal mental health complexes in the northern borders?

7. What are the ways and means to activate the role of the Department of Mental and Social Health in enhancing the performance of social workers working in Al-Amal mental health complexes in the northern borders?

\section{Method and procedures}

The curriculum used: In light of the nature of the study and the goals that it seeks to achieve, and to answer the questions that it raises, the social survey method with a comprehensive quality for social workers working in AlAmal complexes in the northern borders is that it is the most approved scientific curriculum and the most appropriate method of study to obtain the data and information necessary for the study.

Study community: Al Amal Health Complexes in the Northern Borders Region, which employs 400

The study sample: A sample of 85 social workers was selected intentionally.

\section{Study limits: in 2019}

Difficulties encountered by the researcher:

1- There is a dearth of academic and evaluation studies to relieve stress in its various forms from social workers

2- The limited time to carry out this study. As the time is very short compared to the goals set for the study.

\section{Statistical data processing methods:}

The researcher used in processing the study data the statistical methods appropriate to the nature of this study as follows:

1. Pearson correlation coefficient to measure the validity of the internal consistency of the questionnaire items.

2. Cronbach's Alpha factor for calculating the stability of the resolution.

3. Frequencies and percentages to describe the study sample and determine the percentages of their answers.

4. A test of mono-contrast analysis to reveal the differences between the views of the study sample according to their personal variables.

\section{Tenth: The answer to the study's questions:}

Through the main question of the research, which is as follows: What is the impact of social, economic and psychological pressures on the performance of social workers working in Al-Amal Health Complexes in the northern border region?

The opinions of the study sample differed on the effect of social, psychological and economic pressures on social workers in Al-Amal Health Complexes in the Northern Borders Region by means of interview and observation, and the application of the scale was based on a sample of 85 items out of 96 forms submitted.

\section{Data Analyze}

In this part of the research, we will deal with a description of the vocabulary of the study population according to the variables studied, and also the questions of the study will be answered.

\section{Statistical standard:}

The Likart five-step scale was adopted to correct the study tools, by giving each of its paragraphs one of the five grades (strongly agree, agree, neutral, disagree, strongly disagree) and they are digitally represented $(5,4,3,2,1)$ on Arrangement.

\section{Virtual validity}

To ensure the sincerity of the study tool, they were presented to a number of faculty members to take their views about the clarity of their expressions and their suitability of the study questions, and some paragraphs were modified based on the opinions and proposals of the arbitrators.

Where the arbitration was regarding the following aspects:

The extent of clarity of the instructions provided to the individuals of the sample.

- The suitability of alternatives to answers to paragraphs

- The suitability of the number of paragraphs for each dimension.

- The clarity of the linguistic wording of the paragraphs and their content being appropriate to the dimension.

\section{Construction Certification:}

To extract the significance of construction sincerity, the parameters of the correlation of the paragraphs with the total degree were extracted, where the paragraphs were analyzed and the correlation coefficient of each of the paragraphs was calculated, as the correlation coefficient here represents a sign of honesty with respect to each 
paragraph in the form of a correlation coefficient between each paragraph in the field to which it belongs, and the following table Show that

Table (1)

\begin{tabular}{cccccccccccc}
\hline Paragraph no. & $\begin{array}{c}\text { Coefficient } \\
\text { of } \\
\text { correlation } \\
\text { with the } \\
\text { domain }\end{array}$ & $\begin{array}{c}\text { Paragraph } \\
\text { no. }\end{array}$ & $\begin{array}{c}\text { Coefficient } \\
\text { of } \\
\text { correlation } \\
\text { with the } \\
\text { domain }\end{array}$ & $\begin{array}{c}\text { Paragraph } \\
\text { no. }\end{array}$ & $\begin{array}{c}\text { Coefficient } \\
\text { of } \\
\text { correlation } \\
\text { with the } \\
\text { domain }\end{array}$ & $\begin{array}{c}\text { Paragraph } \\
\text { no. }\end{array}$ & $\begin{array}{c}\text { Coefficient } \\
\text { of } \\
\text { correlation } \\
\text { with the } \\
\text { domain }\end{array}$ & $\begin{array}{c}\text { Paragraph } \\
\text { no. }\end{array}$ & $\begin{array}{c}\text { Coefficient } \\
\text { of } \\
\text { correlation } \\
\text { with the } \\
\text { domain }\end{array}$ & $\begin{array}{c}\text { Paragraph } \\
\text { no. }\end{array}$ & $\begin{array}{c}\text { Coefficient } \\
\text { of } \\
\text { correlation } \\
\text { with the } \\
\text { domain }\end{array}$ \\
\hline $\mathbf{1}$ & .721 & 18 & .754 & 35 & .442 & 52 & .641 & 69 & .453 & 86 & $\mathbf{. 5 9 5}$ \\
\hline $\mathbf{2}$ & .668 & 19 & .723 & 36 & .425 & 53 & .632 & 70 & .560 & 87 & $\mathbf{. 6 9 5}$ \\
$\mathbf{3}$ & .725 & 20 & .746 & 37 & .376 & 54 & .538 & 71 & .710 & 88 & $\mathbf{. 7 8 8}$ \\
\hline $\mathbf{4}$ & .801 & 21 & .677 & 38 & $-.066-$ & 55 & .588 & 72 & .687 & 89 & $\mathbf{. 7 6 9}$ \\
$\mathbf{5}$ & .777 & 22 & .734 & 39 & .371 & 56 & .394 & 73 & .682 & 90 & $\mathbf{. 7 6 4}$ \\
$\mathbf{6}$ & .787 & 23 & .832 & 40 & .307 & 57 & .519 & 74 & .653 & 91 & $\mathbf{. 7 8 5}$ \\
$\mathbf{7}$ & .853 & 24 & .731 & 41 & .432 & 58 & .541 & 75 & .677 & 92 & $\mathbf{. 8 6 0}$ \\
\hline $\mathbf{8}$ & .772 & 25 & .710 & 42 & .296 & 59 & .568 & 76 & .673 & 93 & $\mathbf{. 7 5 9}$ \\
$\mathbf{9}$ & .780 & 26 & .803 & 43 & .475 & 60 & .560 & 77 & .512 & 94 & $\mathbf{. 8 3 5}$ \\
$\mathbf{1 0}$ & .800 & 27 & .737 & 44 & .299 & 61 & .492 & 78 & .691 & 95 & $\mathbf{. 8 7 1}$ \\
$\mathbf{1 1}$ & .730 & 28 & .776 & 45 & .354 & 62 & .355 & 79 & .743 & 96 & $\mathbf{. 6 3 0}$ \\
\hline $\mathbf{1 2}$ & .503 & 29 & .742 & 46 & .415 & 63 & .428 & 80 & .747 & 97 & $\mathbf{. 8 9 8}$ \\
$\mathbf{1 3}$ & .757 & 30 & .857 & 47 & .584 & 64 & .420 & 81 & .839 & 98 & $\mathbf{. 9 1 1}$ \\
$\mathbf{1 4}$ & .607 & 31 & .790 & 48 & .573 & 65 & .403 & 82 & .810 & 99 & $\mathbf{. 8 8 0}$ \\
\hline $\mathbf{1 5}$ & .709 & 32 & .676 & 49 & .603 & 66 & .368 & 83 & .799 & 100 & $\mathbf{. 8 9 0}$ \\
\hline $\mathbf{1 6}$ & .675 & 33 & .801 & 50 & .651 & 67 & .396 & 84 & .793 & 101 & $\mathbf{. 8 1 0}$ \\
\hline $\mathbf{1 7}$ & $\mathbf{. 6 7 2}$ & $\mathbf{3 4}$ & $\mathbf{. 8 4 0}$ & $\mathbf{5 1}$ & $\mathbf{. 5 3 0}$ & $\mathbf{6 8}$ & .421 & $\mathbf{8 5}$ & $\mathbf{. 6 9 8}$ & $\mathbf{1 0 2}$ & $\mathbf{. 9 0 1}$ \\
\hline
\end{tabular}

Correlation coefficients between vertebrae and the domain to which they belong, It should be noted that all correlation coefficients were of acceptable and statistically significant degrees, and therefore none of these paragraphs was deleted.

\section{The Stability of the Study Instrument}

The stability coefficient was calculated using the internal consistency method according to the Cronbach alpha equation, and Table No. (2) shows the coherence coefficient according to the Cronbach alpha equation and these values were considered appropriate for the purposes of this study.

Table (2)

The internal consistency coefficient of Cronbach Alpha

\begin{tabular}{|c|c|c|c|}
\hline No. & Fields & $\begin{array}{c}\text { Paragraph } \\
\text { no. }\end{array}$ & $\begin{array}{c}\text { Internal } \\
\text { consistency }\end{array}$ \\
\hline 1 & Anxiety & 18 & .948 \\
\hline 2 & Depression & 16 & .951 \\
\hline 3 & Psychological health & 27 & .866 \\
\hline 4 & Mental and social health & 16 & .834 \\
\hline 5 & Psychological obstacles and challenges & 13 & .933 \\
\hline 6 & $\begin{array}{l}\text { Means necessary to activate the Department of Mental and } \\
\text { Social Health }\end{array}$ & 12 & .961 \\
\hline 7 & The instrument as a whole & 102 & .947 \\
\hline
\end{tabular}


Table (3)

Frequencies and percentages according to the study variables

\begin{tabular}{|c|c|c|c|}
\hline Variables & Categories & Repetition & Percentage \\
\hline \multirow[t]{3}{*}{ Age } & From 20 to less than 30 years old & 43 & 50.6 \\
\hline & From 30 to less than 40 years old & 28 & 32.9 \\
\hline & From 40 to less than 50 years old & 14 & 16.5 \\
\hline \multirow[t]{2}{*}{ Gender } & Male & 57 & 67.1 \\
\hline & female & 28 & 32.9 \\
\hline \multirow[t]{3}{*}{ Academic Level } & Bachelor & 71 & 83.5 \\
\hline & M.A. & 13 & 15.3 \\
\hline & Ph.D. & 1 & 1.2 \\
\hline \multirow[t]{6}{*}{ Experience year } & From day to year & 6 & 7.1 \\
\hline & More than one year to 5 years & 17 & 20.0 \\
\hline & More than 5 years to 10 years & 13 & 15.3 \\
\hline & More than 10 years to 15 years & 23 & 27.1 \\
\hline & More than 15 to 20 years old & 22 & 25.9 \\
\hline & More than 20 to 25 years old & 4 & 4.7 \\
\hline \multirow[t]{5}{*}{ Income level } & Low & 9 & 10.6 \\
\hline & Average & 27 & 31.8 \\
\hline & above average & 41 & 48.2 \\
\hline & high & 8 & 9.4 \\
\hline & Total & 85 & 100.0 \\
\hline
\end{tabular}

It is clear from Table No. (3) that 43 of the study sample represents $50.6 \%$ of the total sample whose ages are less than (20-30) years and they are the most category of the study sample, while (28) of them represent $32.9 \%$ of the total The sample ranges between the ages of less than $(30-40)$ years, compared to 14 of them representing $16.5 \%$ of the total study sample, whose ages range from $(41-50)$ years and they are the lowest category of the study sample as shown by the previous form, as the previous table indicates a percentage Males were the highest of the study sample, as they got $67.1 \%$, while the female percentage was $32.9 \%$.

University education obtained the highest percentage, which was $83.5 \%$ compared to $15.3 \%$, and the PhD degree obtained the lowest year, which was $1.2 \%$. As for the income ratio, it was the highest rate above the average, as it obtained $48.2 \%$ of the total averages, while the rest was distributed The average income is $31.8 \%$, low and high, approximately $10.6 \%$ and 9.4 , respectively.

The first question: What is the role of concern over the performance of social workers working in Al-Amal mental health complexes in the northern borders from their point of view?

To answer this question, arithmetic averages and standard deviations were extracted for paragraphs related to the field of concern for the performance of social workers working in Al-Amal mental health complexes in the northern borders, and the table below shows that.

Table No. (4)

Arithmetic mean and standard deviations of the paragraphs related to the field of concern for the performance of social workers working in Al-Amal mental health complexes in the northern borders, in descending order according to their arithmetic mean.

\begin{tabular}{|c|c|l|c|c|c|}
\hline Rank & No. & \multicolumn{1}{|c|}{ Paragraph } & $\begin{array}{c}\text { Arithmetic } \\
\text { mean }\end{array}$ & $\begin{array}{c}\text { standard } \\
\text { deviations }\end{array}$ & Level \\
\hline $\mathbf{1}$ & $\mathbf{1 2}$ & My focus is high when I work & $\mathbf{4 . 0 5}$ & $\mathbf{7 3 8}$ & High \\
\hline $\mathbf{2}$ & $\mathbf{1 5}$ & I like to be happy as others seem & $\mathbf{4 . 0 0}$ & $\mathbf{. 8 1 6}$ & High \\
\hline $\mathbf{3}$ & $\mathbf{1 4}$ & I do not fear crises and adversity & $\mathbf{3 . 9 6}$ &. $\mathbf{7 7 8}$ & High \\
\hline $\mathbf{4}$ & $\mathbf{8}$ & I feel hungry at all times so much & $\mathbf{3 . 9 3}$ & $\mathbf{9 3 6}$ & High \\
\hline $\mathbf{5}$ & $\mathbf{1 3}$ & I am worried about something or a person. & $\mathbf{3 . 9 1}$ & $\mathbf{8 5 4}$ & High \\
\hline $\mathbf{6}$ & $\mathbf{1 6}$ & Life is hard for me & $\mathbf{3 . 8 1}$ & $\mathbf{. 8 0 9}$ & High \\
\hline $\mathbf{7}$ & $\mathbf{1}$ & My sleep is interrupted & $\mathbf{3 . 7 8}$ & $\mathbf{. 6 9 7}$ & High \\
\hline $\mathbf{8}$ & $\mathbf{5}$ & I am concerned about financial matters & $\mathbf{3 . 6 9}$ & $\mathbf{8 5 9}$ & High \\
\hline $\mathbf{9}$ & $\mathbf{6}$ & I feel hungry at all times so much. & $\mathbf{3 . 6 8}$ & $\mathbf{. 8 6 2}$ & High \\
\hline $\mathbf{1 0}$ & $\mathbf{4}$ & I am worried about work & $\mathbf{3 . 6 7}$ & $\mathbf{. 8 9 2}$ & Moderate \\
\hline $\mathbf{1 1}$ & $\mathbf{1 8}$ & I cry easily & $\mathbf{3 . 6 4}$ & $\mathbf{8 5 7}$ & Moderate \\
\hline $\mathbf{1 2}$ & $\mathbf{1 1}$ & I feel happy most of the time. & $\mathbf{3 . 6 2}$ & $\mathbf{. 7 8 6}$ & Moderate \\
\hline $\mathbf{1 3}$ & $\mathbf{3}$ & I have bad dreams & $\mathbf{3 . 6 0}$ & $\mathbf{8 4 8}$ & Moderate \\
\hline
\end{tabular}




\begin{tabular}{|c|c|l|c|c|c|}
\hline Rank & No. & \multicolumn{1}{|c|}{ Paragraph } & $\begin{array}{c}\text { Arithmetic } \\
\text { mean }\end{array}$ & $\begin{array}{c}\text { standard } \\
\text { deviations }\end{array}$ & Level \\
\hline $\mathbf{1 4}$ & $\mathbf{9}$ & I am usually quiet & $\mathbf{3 . 5 1}$ & $\mathbf{9 2 1}$ & Moderate \\
\hline $\mathbf{1 5}$ & $\mathbf{7}$ & It makes me wait nervous & $\mathbf{3 . 4 6}$ & $\mathbf{. 8 6 7}$ & Moderate \\
\hline $\mathbf{1 5}$ & $\mathbf{1 7}$ & $\begin{array}{l}\text { I am concerned about the possible ill- } \\
\text { treatment I might encounter }\end{array}$ & $\mathbf{3 . 4 6}$ & $\mathbf{9 5 8}$ & Moderate \\
\hline $\mathbf{1 7}$ & $\mathbf{1 0}$ & I can't sit long in my place & $\mathbf{3 . 3 8}$ & $\mathbf{. 9 3 8}$ & Moderate \\
\hline $\mathbf{1 8}$ & $\mathbf{2}$ & I think I am more nervous than most people & $\mathbf{3 . 3 2}$ & $\mathbf{. 9 6 6}$ & Moderate \\
\hline & Anxiety as a whole & $\mathbf{. 6 2 4}$ & $\mathbf{. 6 2 4}$ & High \\
\hline
\end{tabular}

Table (4) shows that the arithmetic averages ranged between (3.32-4.05), where paragraph No. (12) stipulated "my concentration is high when I work" in the first place with an average score of (4.05), while paragraph No. (2) "I think I am more nervous than most people," she said, with an average score of 3.32. The mean of the anxiety as a whole was (3.69).

The second question: What is the role of depression on the performance of social workers working in AlAmal mental health complexes in the northern borders from their point of view?

To answer this question, mathematical averages and standard deviations for the depression-related items on the performance of social workers working in Al-Amal mental health complexes in the northern borders were extracted, and the table below shows that.

Table No. (5)

The arithmetic mean and the standard deviations of the paragraphs related to the field of depression on the performance of social workers working in Al-Amal mental health complexes in the northern borders, in descending order according to their arithmetic mean.

\begin{tabular}{|c|c|c|c|c|c|}
\hline Rank & No. & Paragraph & arithmetic mean & standard deviation & level \\
\hline 1 & 20 & Confusion at work bothering me & 3.85 & .866 & High \\
\hline 2 & 19 & I am very vulnerable to events & 3.81 & .919 & High \\
\hline 3 & 21 & I am more sensitive than most people. & 3.80 & .737 & High \\
\hline 3 & 27 & Save myself because of my weakness & 3.80 & .856 & High \\
\hline 5 & 25 & I feel guilty most of the time & 3.76 & .882 & High \\
\hline 6 & 23 & Enjoy enough aspects of life & 3.71 & .828 & High \\
\hline 7 & 26 & I feel dissatisfied with myself & 3.62 & .976 & Moderate \\
\hline 8 & 22 & I'm very nervous while doing something & 3.59 & .930 & Moderate \\
\hline 9 & 31 & I lost interest in most people around me & 3.54 & .780 & Moderate \\
\hline 10 & 33 & I feel worse than others & 3.48 & .868 & Moderate \\
\hline 11 & 30 & Get upset faster than before & 3.41 & .849 & Moderate \\
\hline 12 & 24 & Pessimistic for the future & 3.39 & 1.013 & Moderate \\
\hline 13 & 34 & I feel my appearance as fit as it used to be & 3.32 & .978 & Moderate \\
\hline 14 & 29 & I cry now more than before & 3.28 & .734 & Moderate \\
\hline 15 & 28 & I love life & 3.24 & .797 & Moderate \\
\hline 16 & 32 & I find it difficult to make a decision & 2.99 & .945 & Moderate \\
\hline & & Depression as a whole & & .664 & \\
\hline
\end{tabular}

Table (5) shows that the arithmetic mean ranged between (2.99-3.85), as paragraph (20) stated that "My confusion at work annoys me" is in the first place with an arithmetic average of (3.85), while paragraph (32) came Its text says, "I find it difficult to make a decision" at the last rank, with an average score of (2.99). The mean for depression as a whole was 3.54 .

The third question: What is the level of mental health and social performance of social workers working in Al-Amal mental health complexes in the northern borders?

To answer this question, average scores and standard deviations for mental health were extracted for social workers working in Al-Amal mental health complexes in the northern borders and their performance, and the table below shows that. 
Table No (6)

The arithmetic mean and the standard deviations of mental health for social workers working in Al-Amal mental health complexes in the northern borders and their performance is in descending order according to the arithmetic mean for them

\begin{tabular}{|c|c|c|c|c|c|}
\hline Rank & No. & Paragraph & arithmetic mean & $\begin{array}{c}\text { standard } \\
\text { deviations }\end{array}$ & Level \\
\hline 1 & 61 & I feel nervous if you run into my boss & 4.09 & .750 & High \\
\hline 2 & 45 & I suffer from insomnia for a long time & 4.06 & .850 & High \\
\hline 3 & 47 & $\begin{array}{l}\text { Repeated frustration makes my life } \\
\text { meaningless }\end{array}$ & 3.95 & .671 & High \\
\hline 4 & 37 & I feel happy & 3.93 & .897 & High \\
\hline 4 & 54 & I feel it is difficult to make decisions & 3.93 & .720 & High \\
\hline 6 & 60 & I feel safety & 3.92 & .929 & High \\
\hline 7 & 58 & People consider me hard & 3.91 & .811 & High \\
\hline 8 & 43 & I feel that my physical future is unstable & 3.80 & .998 & High \\
\hline 9 & 46 & I find no difficulty in my material life & 3.79 & .888 & High \\
\hline 10 & 41 & I suffer from insomnia for a long time & 3.78 & .850 & High \\
\hline 11 & 59 & My business is valuable & 3.75 & .844 & High \\
\hline 12 & 51 & Sometimes I feel a headache & 3.72 & .840 & High \\
\hline 13 & 35 & I feel disappointed in myself & 3.71 & .857 & High \\
\hline 14 & 36 & $\begin{array}{l}\text { I feel satisfied with myself despite the } \\
\text { stresses of life. }\end{array}$ & 3.68 & .848 & High \\
\hline 15 & 39 & My high spirits & 3.65 & .719 & Moderate \\
\hline 16 & 50 & I feel desperate quickly & 3.61 & .977 & Moderate \\
\hline 17 & 42 & $\begin{array}{l}\text { Some of my relatives suffer from some } \\
\text { mental illness }\end{array}$ & 3.60 & .819 & Moderate \\
\hline 17 & 57 & $\begin{array}{l}\text { I understand the instructions and orders } \\
\text { are constantly wrong }\end{array}$ & 3.60 & .966 & Moderate \\
\hline 19 & 40 & I feel fear for no reason since childhood & 3.55 & .779 & Moderate \\
\hline 20 & 49 & Feel true happiness found in my life & 3.52 & .983 & Moderate \\
\hline 21 & 52 & I accept myself when I fail in my duties & 3.49 & .908 & Moderate \\
\hline 22 & 48 & $\begin{array}{l}\text { My life is full of sadness, despite the few } \\
\text { problems with it }\end{array}$ & 3.48 & .983 & Moderate \\
\hline 23 & 56 & I feel bad when I eat at home & 3.42 & .943 & Moderate \\
\hline 24 & 53 & Sometimes I feel weak & 3.36 & .937 & Moderate \\
\hline 25 & 44 & I feel happy & 3.27 & 1.062 & Moderate \\
\hline 26 & 55 & I feel a good specialist & 3.24 & .882 & Moderate \\
\hline 27 & 38 & A while ago, Elias filled my life & 3.09 & .366 & Moderate \\
\hline & & & $\begin{array}{l}\text { Mental health as a } \\
\text { whole }\end{array}$ & .408 & Moderate \\
\hline
\end{tabular}

Table (6) shows that the arithmetic averages ranged between (4.09-3.09), where paragraph No. (61) states, "I feel nervous if I face my boss at work" came first and with an average of (4.09), while paragraph No. (38) And it reads: "A while ago, Elias filled my life" with the last rank, with an average score of (3.09). The mean arithmetic for mental health as a whole was (3.66).

Fourth Question: What is the level of mental and social health and the performance of social workers working in Al-Amal mental health complexes in the northern borders?

To answer this question, mathematical averages and standard deviations for mental and social health and the performance of social workers working in Al-Amal mental health complexes in the northern borders were extracted, and the table below shows that. 
Table No. (7)

Arithmetic mean and standard deviations for mental and social health and the performance of social workers working in Al-Amal mental health complexes in the northern borders are arranged in descending order according to their arithmetic mean.

\begin{tabular}{|c|c|l|c|c|c|}
\hline Rank & No. & \multicolumn{1}{|c|}{ Paragraph } & $\begin{array}{c}\text { arithmetic } \\
\text { mean }\end{array}$ & $\begin{array}{c}\text { standard } \\
\text { deviations }\end{array}$ & Level \\
\hline $\mathbf{1}$ & $\mathbf{6 5}$ & I need to develop my skills & $\mathbf{3 . 8 7}$ & $\mathbf{. 7 0 4}$ & High \\
\hline $\mathbf{2}$ & $\mathbf{6 7}$ & My behavior is affected by the nature of my work & $\mathbf{3 . 8 1}$ & $\mathbf{. 9 8 2}$ & High \\
\hline $\mathbf{2}$ & $\mathbf{7 0}$ & The nature of the venue affects my performance & $\mathbf{3 . 8 1}$ & $\mathbf{. 9 9 4}$ & High \\
\hline $\mathbf{4}$ & $\mathbf{6 6}$ & I deal with multiple groups in society & $\mathbf{3 . 8 0}$ & $\mathbf{. 8 7 0}$ & High \\
\hline $\mathbf{5}$ & $\mathbf{6 2}$ & I earn a salary that matches my capabilities & $\mathbf{3 . 7 4}$ & $\mathbf{. 7 7 4}$ & High \\
\hline $\mathbf{6}$ & $\mathbf{6 8}$ & My poor adaptation to my work makes me nervous & $\mathbf{3 . 5 4}$ & $\mathbf{. 9 3 3}$ & Moderate \\
\hline $\mathbf{7}$ & $\mathbf{6 4}$ & I find it difficult to do my job because of social pressure & $\mathbf{3 . 5 2}$ & $\mathbf{. 9 2 1}$ & Moderate \\
\hline $\mathbf{8}$ & $\mathbf{6 9}$ & $\begin{array}{l}\text { There is training that helps me be patient in dealing with } \\
\text { different types of people }\end{array}$ & $\mathbf{3 . 4 5}$ & $\mathbf{. 8 5 2}$ & Moderate \\
\hline $\mathbf{9}$ & $\mathbf{7 5}$ & I can control my emotions & $\mathbf{3 . 3 3}$ & $\mathbf{1 . 2 0 9}$ & Moderate \\
\hline $\mathbf{1 0}$ & $\mathbf{7 6}$ & I need to develop my skills & $\mathbf{3 . 2 8}$ & $\mathbf{1 . 0 5 3}$ & Moderate \\
\hline $\mathbf{1 1}$ & $\mathbf{6 3}$ & I can achieve my goals & $\mathbf{3 . 2 5}$ & $\mathbf{. 7 8 5}$ & Moderate \\
\hline $\mathbf{1 2}$ & $\mathbf{7 1}$ & I have a great responsibility towards cases & $\mathbf{3 . 1 6}$ & $\mathbf{1 . 1 5 3}$ & Moderate \\
\hline $\mathbf{1 2}$ & $\mathbf{7 4}$ & $\begin{array}{l}\text { If the place is not suitable for the session, it makes me } \\
\text { disliked by the atmosphere of the work }\end{array}$ & $\mathbf{3 . 1 6}$ & $\mathbf{1 . 1 6 3}$ & Moderate \\
\hline $\mathbf{1 4}$ & $\mathbf{7 3}$ & I can control my nervousness & $\mathbf{3 . 1 1}$ & $\mathbf{1 . 2 0 5}$ & Moderate \\
\hline $\mathbf{1 5}$ & $\mathbf{7 2}$ & $\begin{array}{l}\text { I find the right place to work by providing a well- } \\
\text { ventilated environment }\end{array}$ & $\mathbf{3 . 0 9}$ & $\mathbf{1 . 1 5 1}$ & Moderate \\
\hline $\mathbf{1 6}$ & $\mathbf{7 7}$ & $\begin{array}{l}\text { He had to avoid exerting effort at work, which affects } \\
\text { the outcome of cases }\end{array}$ & $\mathbf{2 . 9 6}$ & $\mathbf{1 . 1 7 0}$ & Moderate \\
\hline & & Mental and social health as a whole & $\mathbf{. 5 4 0}$ & \\
\hline
\end{tabular}

Table (7) shows that the arithmetic mean ranged between (3.87-2.96), as paragraph (65) stated that "I need to develop my skills" in the first place with an average of (3.77), while paragraph (77) It reads, "I feel happy about achieving my goals," with the last average, with an average score of (2.96). The mean of the mental and social health as a whole was (3.43.(

Fifth question: Are there statistically significant differences at the level of significance $(\alpha=0.05)$ between the estimates of the study sample individuals on the management of mental and social health in enhancing the performance of social workers working in Al-Amal mental health complexes in the northern borders due to the variables (gender, educational qualification, years of service(

To answer this question, arithmetic averages and standard deviations were extracted from the Department of Mental and Social Health in enhancing the performance of social workers working in Al-Amal mental health complexes in the northern borders according to variables (gender, educational qualification, years of service), and the table below shows that.

Table No. (8)

Arithmetic mean and standard deviations for the Department of Mental and Social Health in enhancing the performance of social workers working in Al-Amal Complex for Mental Health in the northern borders according to variables (gender, educational qualification, years of service).

\begin{tabular}{|c|c|c|c|c|}
\hline \multirow{3}{*}{$\begin{array}{c}\text { Variable } \\
\text { gender }\end{array}$} & Categories & Average & deviations & No. \\
\hline & Male & 3.29 & .941 & 57 \\
\hline & Female & 3.08 & .935 & 28 \\
\hline \multirow[t]{3}{*}{ qualification } & Bachelor & 3.26 & .926 & 71 \\
\hline & M.A. & 3.03 & 1.052 & 13 \\
\hline & Ph.D. & 2.92 & .001 & 1 \\
\hline \multirow[t]{6}{*}{ Years of service } & From day to year & 3.31 & .911 & 6 \\
\hline & More than one year to 5 years & 2.98 & .890 & 17 \\
\hline & More than 5 years to 10 years & 3.10 & .875 & 13 \\
\hline & More than 10 years to 15 years & 3.01 & .900 & 23 \\
\hline & More than 15 to 20 years old & 3.62 & .951 & 22 \\
\hline & More than 20 to 25 years old & 3.56 & 1.286 & 4 \\
\hline
\end{tabular}

Table (8) shows an apparent variation in arithmetic averages and standard deviations of the Department of Mental and Social Health in enhancing the performance of social workers working in Al-Amal mental health 
complexes in the northern borders due to the different categories of gender variables, educational qualification, years of service. To show the significance of the statistical differences between the arithmetic averages, the ANOVA variance analysis was used.

Table No. (9)

ANOVA Triangular Analysis of Age Impact Gender, Qualification, Years of Service on Mental and Social Health Administration in Enhancing the Performance of Social Workers Working in Al-Amal Complex for Mental Health in the Northern Borders

\begin{tabular}{|c|c|c|c|c|c|}
\hline $\begin{array}{c}\text { Source of } \\
\text { contrast }\end{array}$ & $\begin{array}{c}\text { Sum of } \\
\text { squares }\end{array}$ & $\begin{array}{c}\text { Degrees of } \\
\text { freedom }\end{array}$ & $\begin{array}{c}\text { Average } \\
\text { squares }\end{array}$ & $\begin{array}{c}\text { F } \\
\text { Value }\end{array}$ & $\begin{array}{c}\text { Statistical } \\
\text { significance }\end{array}$ \\
\hline Gender & $\mathbf{1 . 1 1 9}$ & 1 & 1.119 & 1.287 & .260 \\
\hline Qualification & .774 & 2 & .387 & .445 & .642 \\
\hline Years of service & $\mathbf{6 . 4 0 5}$ & 5 & 1.281 & 1.474 & .208 \\
\hline The error & $\mathbf{6 6 . 0 3 7}$ & 76 & .869 & & \\
\hline Overall & $\mathbf{7 4 . 0 4 7}$ & $\mathbf{8 4}$ & & & \\
\hline
\end{tabular}

The following table (-) shows:

-There were no statistically significant differences $(\mathrm{a}=0.05)$ due to the effect of gender, where the value of $\mathrm{P}$ was (1.287) and with statistical significance of (260).

-There were no statistically significant differences $(\mathrm{a}=0.05)$ due to the effect of the educational qualification, as the value of $P(.445)$ and with statistical significance reached (.642).

-There were no statistically significant differences $(a=0.05)$ due to the effect of years of service, where the value of $\mathrm{P}$ was (1.474) and with statistical significance of (.208).

The sixth question: What are the psychological obstacles and challenges facing social workers working in AlAmal mental health complexes in the northern borders?

To answer this question, arithmetic averages and standard deviations for psychological obstacles and challenges facing social workers working in Al-Amal mental health complexes in the northern borders were extracted, and the table below shows that.

Table No. (10)

Arithmetic mean and standard deviations for psychological obstacles and challenges facing social workers working in Al-Amal mental health complexes in the northern borders are arranged in descending order according to their arithmetic mean

\begin{tabular}{|c|c|c|c|c|c|}
\hline Rank & No. & Paragraph & $\begin{array}{l}\text { arithmetic } \\
\text { mean }\end{array}$ & $\begin{array}{c}\text { standard } \\
\text { deviations }\end{array}$ & Level \\
\hline 1 & 80 & $\begin{array}{l}\text { I find that economic conditions affect my } \\
\text { thinking }\end{array}$ & 3.66 & 1.018 & Moderate \\
\hline 2 & 83 & $\begin{array}{l}\text { I feel aggression due to bad economic } \\
\text { conditions }\end{array}$ & 3.59 & .979 & Moderate \\
\hline 3 & 81 & I feel a failure in my life & 3.56 & .892 & Moderate \\
\hline 4 & 90 & I feel hopeless in the future & 3.55 & 1.064 & Moderate \\
\hline 5 & 84 & I feel financial insecurity & 3.52 & .971 & Moderate \\
\hline 6 & 82 & $\begin{array}{l}\text { My behavior is affected by the nature of my } \\
\text { work }\end{array}$ & 3.51 & .971 & Moderate \\
\hline 7 & 89 & $\begin{array}{l}\text { The psychological state affects my } \\
\text { productivity as a specialist }\end{array}$ & 3.48 & 1.087 & Moderate \\
\hline 8 & 87 & Mental health is essential in the workplace & 3.46 & 1.119 & Moderate \\
\hline 9 & 88 & $\begin{array}{l}\text { Mental health helps in achieving an } \\
\text { integrated personality }\end{array}$ & 3.39 & 1.124 & Moderate \\
\hline 10 & 85 & Express my emotions in a balanced manner & 3.36 & .784 & Moderate \\
\hline 11 & 86 & Mental health is important to society & 3.35 & 1.110 & Moderate \\
\hline 12 & 79 & $\begin{array}{l}\text { I find that I need new training to achieve } \\
\text { results with cases }\end{array}$ & 3.04 & 1.085 & Moderate \\
\hline 13 & 78 & I find a lack of focus in my work & 3.00 & 1.134 & Moderate \\
\hline & & $\begin{array}{l}\text { Psychological obstacles and challenges as a } \\
\text { whole }\end{array}$ & & .767 & \\
\hline
\end{tabular}

Table (10) shows that the arithmetic averages ranged between (3.00-3.66), as paragraph (86) which states "mental health is important to society" came first and with an average of (3.66), while paragraph (78) came Its text says, "I find a lack of focus in my work" in the last rank, with an average score of (3.00). The mean of psychological disabilities and challenges as a whole was (3.42). 
Question Seven: What are the necessary means and means to activate the role of the Department of Mental and Social Health in enhancing the performance of social workers working in Al-Amal mental health complexes in the northern borders?

To answer this question, arithmetic averages and standard deviations were extracted for the means and means necessary to activate the role of the Department of Mental and Social Health in enhancing the performance of social workers working in Al-Amal mental health complexes in the northern borders, and the table below illustrates this.

Table No. (11)

Arithmetic mean and standard deviations of the means and means necessary to activate the role of the Department of Mental and Social Health in enhancing the performance of social workers working in AlAmal mental health complexes in the northern borders are arranged in descending order according to the arithmetic mean for them

\begin{tabular}{|c|c|c|c|c|c|}
\hline Rank & No. & Paragraph & $\begin{array}{c}\text { arithmetic } \\
\text { mean }\end{array}$ & $\begin{array}{c}\text { standard } \\
\text { deviations }\end{array}$ & Level \\
\hline 1 & 94 & $\begin{array}{l}\text { Spreading a culture is important to a social } \\
\text { worker }\end{array}$ & 3.53 & 1.019 & Moderate \\
\hline 2 & 91 & $\begin{array}{l}\text { I find that training in all developments of the } \\
\text { profession helps me }\end{array}$ & 3.45 & 1.097 & Moderate \\
\hline 2 & 93 & $\begin{array}{l}\text { Work improvement programs for social } \\
\text { workers }\end{array}$ & 3.45 & 1.041 & Moderate \\
\hline 4 & 95 & $\begin{array}{l}\text { Psychological programs must be created to } \\
\text { support specialists }\end{array}$ & 3.28 & 1.171 & Moderate \\
\hline 5 & 98 & $\begin{array}{l}\text { Providing environmentally appropriate places } \\
\text { for the social worker }\end{array}$ & 3.24 & 1.202 & Moderate \\
\hline 6 & 96 & Training courses to support the social worker & 3.19 & .681 & Moderate \\
\hline 6 & 100 & $\begin{array}{l}\text { The need to pay attention to the work of a } \\
\text { specialist in society }\end{array}$ & 3.19 & 1.200 & Moderate \\
\hline 8 & 92 & find psychological support for social workers & 3.18 & 1.157 & Moderate \\
\hline 9 & 99 & $\begin{array}{l}\text { Spreading a culture of the role of the social } \\
\text { worker is important }\end{array}$ & 3.12 & 1.128 & Moderate \\
\hline 10 & 97 & $\begin{array}{l}\text { Provide the appropriate physical tools for the } \\
\text { specialist }\end{array}$ & 3.06 & 1.209 & Moderate \\
\hline 11 & 102 & $\begin{array}{l}\text { Make specific courses to work as a social } \\
\text { worker }\end{array}$ & 3.02 & 1.165 & Moderate \\
\hline 12 & 101 & $\begin{array}{l}\text { The work of a body or association responsible } \\
\text { for solving specialist problems }\end{array}$ & 2.98 & 1.272 & Moderate \\
\hline & & $\begin{array}{l}\text { Means necessary to activate the Department of } \\
\text { Mental and Social Health as a whole }\end{array}$ & & .939 & \\
\hline
\end{tabular}

Table (11) shows that the arithmetic mean ranged between (2.98-3.53), where paragraph (94) which states "spreading a culture in the role of the importance of the social worker" came first and with an arithmetic mean of (3.53), while paragraph No. ( 101) The text says, "The work of a body or association responsible for solving specialist problems" is ranked last, with an average of (2.98). The mean of the means necessary to activate the Department of Mental and Social Health as a whole was (3.22),

\section{Conclusion}

The profession of social worker these days tends to work long hours of the day and deal with various activities and pay attention to the problems that customers are located in order to help them solve what affects their psychological and health condition and this besides social and economic pressures so that he lives a condition appropriate to the requirements of the times all of these factors led to doing With this study, to find scientific and practical solutions for the mitigation of the social worker so that his work can be performed easily and easily, because if we overlook these existing problems for this important group in society, the community will afflict many social diseases in addition to the reluctance of members of society in all its categories (males / Females) from working in the social field, and consequently, the deterioration of society, which was in a way to evolve, develop, and join advanced nations.

\section{Results}

1. The results of the existence of a role for concern on the performance of social workers working in Al-Amal complexes for mental health in the northern borders from their point of view, where the results of the study agreed 
with the study of Al-Halim (2015) that stresses, whether from work or from humans affect the nerves, so it should try to reduce Them or get rid of them, and how to deal with them by learning how to confront them and stand up to them.

2. The study also showed a role for depression on the performance of social workers working in Al-Amal mental health complexes in the northern borders from their point of view. The results of the study, Shawkat (2013), agreed to the effect of "psychological stress" that extends to the various aspects of the worker, his physical and psychological health in addition to productivity The organization and its performance, which reflects negatively on the whole society, hence the importance of caring to find appropriate solutions to deal with "psychological stress" to reduce it or keep it within the normal level.

3.. The study also showed that there is a role for mental health in the performance of social workers working in Al-Amal mental health complexes in the northern borders and their performance from their point of view.

4. The study also revealed the existence of psychological obstacles and challenges facing social workers working in Al-Amal mental health complexes in the northern borders, the most important of which are economic conditions, as the study concluded that the social worker is concerned with many economic conditions.

1. The study also showed the following results:

- There are statistically significant differences according to the effect of anxiety according to the family's support among the social workers at Al-Amal Complex for Mental Health in the northern region.

- There are statistically significant differences according to the effect of depression according to the income level of the social workers in Al-Amal Complex for Mental Health in the northern region.

- There are statistically significant differences according to the effect of "psychological stress" on social workers

in Al-Amal Complex for Mental Health in the northern region, according to psychological rigidity.

2. The study also showed that the means to activate the Department of Mental and Social Health are:

1- Awareness programs must be made about the importance of the role of social workers.

2- The work of psychological support programs for social workers, and that it is a regular.

3- Providing the appropriate tools and suitable workplaces for the performance of the social worker.

4- Training courses to develop the work of the social worker.

5- Pay attention to all the notes and their application that the social worker makes clear to solve problems at their roots.

6- Spreading the culture of relying on the social worker for solving various problems and confidence in his performance.

7- Providing accredited courses to pass certain tests to work in the social field and creating a body for social specialties, such as the Health Specializations Authority.

\section{Recommendations}

1- Supporting the social worker by increasing salaries to alleviate economic pressures.

2- Providing courses to develop the skills of the social worker to deal with the requirements of the times and gain new experiences in dealing with clients.

3- Developing family awareness in the media of the importance of the family's role in alleviating the pressures of its members, especially since the family plays an important role in this.

\section{References}

1. Saudi, Ahmed Faraj (2009) Work Stress and Proposals for a Solution !, Management, Vol 47, No. 2, Union of Administrative Development Associations.

2. Al-Rantisi, Ahmed Mohamed (2017) The relationship between stress and professional fatigue of social workers working in the directorates of social affairs - a study applied to social workers working in social affairs directorates in the Gaza Strip, Journal of Islamic Research for Humanitarian Research, No. 25, Volume 1.

3. Abdullah, Alaa Kamal Ahmed Mohamed (2018) "Psychological Stress" and its relationship to aggressive behavior among the students of Sudan University of Science and Technology, MA, Department of Criminal Psychology, Institute of Criminal and Social Studies and Research, National Rabat University.

4. Al-Hamlan, Amal Falah Fahd (2008) Psychological Burnout and Social Support and their relationship towards Kuwaiti workers towards early retirement (psychometric-clinical study), MA, Department of Mental Health, College of Education, Zagazig University.

5. The Soldier, Amina Al-Sayed and Nabila Michael Makary (2007): "Psychological Stress" as perceived by teachers of applied subjects at the secondary level, Egyptian Journal of Psychological Studies, 17, (55), pp. 53-57.

6. Al-Sarafi, Inaam Qassem Khafif (2011) "Psychological Stress" and its relationship to some variables among university students, filling 20736592, document number 122206, Journal of the College of Education for Pure Sciences. Mg. 1, p. 5, Pages; 155-184, Iraq. Dhi Qar University

7. Bin Masmoudi, Ali (2011) Psychological Stress and Coping Strategies, Al-Hikma Magazine, Kunooz Al-Hikma 
Foundation for Publishing and Distribution, p. 7, pages 55 - 60, ISSN :; 9662-1112, MD number: 652531, Algeria

8. Ahmed, Doaa Magdy Eid (2015) Social and physical pressures and their implications on the methods of social and environmental compatibility for women in polygamous cases, Ph.D., Ain Shams University - Institute of Environment - Department of Environmental Humanities, Egypt.

9. Shawkat, Rana Rifaat (2013) The pressures that social researchers are exposed to and their relationship to job satisfaction, AR 205, Professor, Baghdad University - Ibn Rushd College of Education, Iraq, pp. 693-718, ISSN: 0552-265X

10. Abu Zaid, Soha Helmy (2015), Methods of Social Workers Dealing with Occupational Stress Affecting the Effectiveness of Their Performance in Working with School Groups, Journal of Studies in Social Work and Humanities, Helwan University - College of Social Work, AR 39, C 14, October, Egypt Pp. 65--129

11. Bouchaaria, Salha Muhammad Yunus (2012) Life pressures, Journal of Scientific Research in Arts, Ain Shams University - Girls College of Arts, Sciences and Education, p. 13, Supplement, Pages :; 503-527, ISSN :; 8321-2356, MD number: 760777, Egypt

12. Abdel Halim, Adel (2015) Haider, Life Stress and Confrontation Skills, Security and Life, Naif Arab University for Security Sciences, Vol. 35, No. 401, September, Saudi Arabia, Pages: 78 - 83

13. Ahmed, Abdel-Jaber El-Sayed (2014) Social Stress and its Relationship with the Quality of Professional Performance of Social Workers in Al-Azhar Institutes, Assiut University - Faculty of Social Work - Individual Service, MA.

14. Wilkinson, Greg (2013), Stress (First Edition), Saudi Arabia-Riyadh: Arabic Books.

15. Al Darebe, Muhammad (2010) Methods of Confronting Occupational Psychological Stress and its Relationship with Some Variables “A Field Study on a Sample of Workers at the Footwear Factory in Damascus” Journal of Damascus University - Volume 26 - Fourth Issue

16. Al-Qiheem, Miteb Bin Musleh Bin (2004) Attitudes of drug addiction patients towards the role of the social worker - a field study on the complexes of hope in the Kingdom of Saudi Arabia in Riyadh, Jeddah and Dammam, MA, Naif Al-Areya University for Security Sciences, Department of Social Sciences, specializing in rehabilitation and parish Social .

17. Qandil, Mohamed Mohamed Bassiouni (2015), a suggested counseling program from the perspective of group service to confront the negative effects of professional pressures facing the social worker in the medical field, Journal of Studies in Social Work and Humanities, Helwan University - College of Social Work, p. 38, c 6, Egypt, Pages :; 1081 - 1122

18- Wadman, Ruth; Durkin, Kevin; Conti-Ramsden, Gina(2011-06-01). "Social stress in young people with specific language impairment". Journal of Adolescence. 34 (3): 421-431. doi:10.1016/j.adolescence.2010.06.010.

19- Dormann, Christian; Zapf, Dieter (January 2004). "Customer-Related Social Stressors and Burnout". Journal of Occupational Health Psychology (9.1)

20- Chris Lloyd,Robert King \&Lesley Chenoweth(2009)Social work, stress and burnout: A reviewPages 255265 | Published online: 06 Jul 2009Download citationhttps://doi.org/10.1080/09638230020023642

21- Hansung Kim \&Madeleine Stoner ,2008, Burnout and Turnover Intention Among Social Workers: Effects of Role Stress, Job Autonomy and Social Support ,ages 5-25 | Published online: 12 Oct 2008https://doi.org/10.1080/03643100801922357

22- M. Alex Wagaman, Jennifer M. Geiger, Clara Shockley, Elizabeth A. Segal, 2015, The Role of Empathy in Burnout, Compassion Satisfaction, and Secondary Traumatic Stress among Social Workers,Social Work, Volume 60, Issue 3, July 2015, Pages 201-209, https://doi.org/10.1093/sw/swv014,Published: 01 May 2015 Article history

23- Abdul Wahab Mohammed Al-Dhafiri,2011,The impact of Stressful Event On SocialWork Performance, Micah Edelson1, Tali Sharot,Raymond J. Dolan, Yadin Dudai,2011,Following the Crowd: Brain Substrates of Long-Term Memory Conformity,Science 01 Jul 2011:Vol. 333, Issue 6038, pp. 108-111DOI: $10.1126 /$ science. 1203557 